\title{
Beyond Genes: Germline Disruption in the Etiology of Autism Spectrum Disorders
}

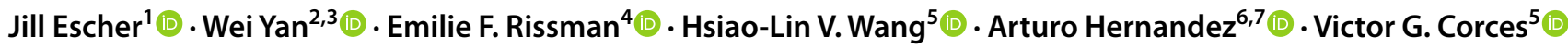

Accepted: 21 September 2021 / Published online: 1 October 2021

(c) The Author(s) 2021

\begin{abstract}
Investigations into the etiology of autism spectrum disorders have been largely confined to two realms: variations in DNA sequence and somatic developmental exposures. Here we suggest a third route-disruption of the germline epigenome induced by exogenous toxicants during a parent's gamete development. Similar to cases of germline mutation, these molecular perturbations may produce dysregulated transcription of brain-related genes during fetal and early development, resulting in abnormal neurobehavioral phenotypes in offspring. Many types of exposures may have these impacts, and here we discuss examples of anesthetic gases, tobacco components, synthetic steroids, and valproic acid. Alterations in parental germline could help explain some unsolved phenomena of autism, including increased prevalence, missing heritability, skewed sex ratio, and heterogeneity of neurobiology and behavior.
\end{abstract}

Keywords Germ cells $\cdot$ Epigenetics $\cdot$ Genetic toxicology $\cdot$ Non-genetic inheritance $\cdot$ Autism spectrum disorder $\cdot$ Gene expression

\section{Introduction}

In the domain of autism spectrum disorder (ASD, or autism) and neurodevelopmental pathology research, it is commonly assumed that the etiological processes of concern are limited to variations in DNA sequence or somatic environmental insults (Dietz et al., 2020; Lord et al., 2020). In this commentary, we propose that this binary approach- "genetics"

Jill Escher

jill.escher@gmail.com

1 Escher Fund for Autism, 1590 Calaveras Avenue, San Jose, CA, USA

2 The Lundquist Institute for Biomedical Innovation at Harbor-UCLA Medical Center, Torrance, CA, USA

3 Department of Medicine, David Geffen School of Medicine at UCLA, Los Angeles, CA, USA

4 Center for Human Health and the Environment and Department of Biological Sciences, North Carolina State University, Raleigh, NC, USA

5 Department of Human Genetics, Emory University School of Medicine, Atlanta, GA, USA

6 Maine Medical Center Research Institute, MaineHealth, Scarborough, ME, USA

7 Tufts University School of Medicine, Boston, MA, USA or "environment" - is incomplete as it overlooks another critical dimension of risk for neurodevelopmental disorders. Specifically, we suggest that exogenously induced germ cell perturbations, including but not limited to disruptions of the transcriptional machinery, chromatin structure/organization, or other epigenomic information such as non-coding RNAs, contribute to the heritable risk for neurodevelopmental pathology, which may manifest as autism or related disorders (Fig. 1).

To be clear, this "germline disruption" hypothesis is not addressing what is often referred to as "genes by environment," or the possibility that environmental factors influence gene expression during the course of fetal or early development, which is best understood as a subcategory of somatic exposure. Rather, we focus on exposures to, and perturbations of, the germline of the affected individual's parent(s) over the course of the parental gametogenesis. These insults to the germline may occur at various life stages, beginning when primordial germ cells are initially formed in the parents during embryonic life, continuing through puberty to the time of conception of the next generation, thus providing a prolonged opportunity for multiple types of exposures to disrupt transcriptional, epigenetic, or genetic programs (Fig. 1). 


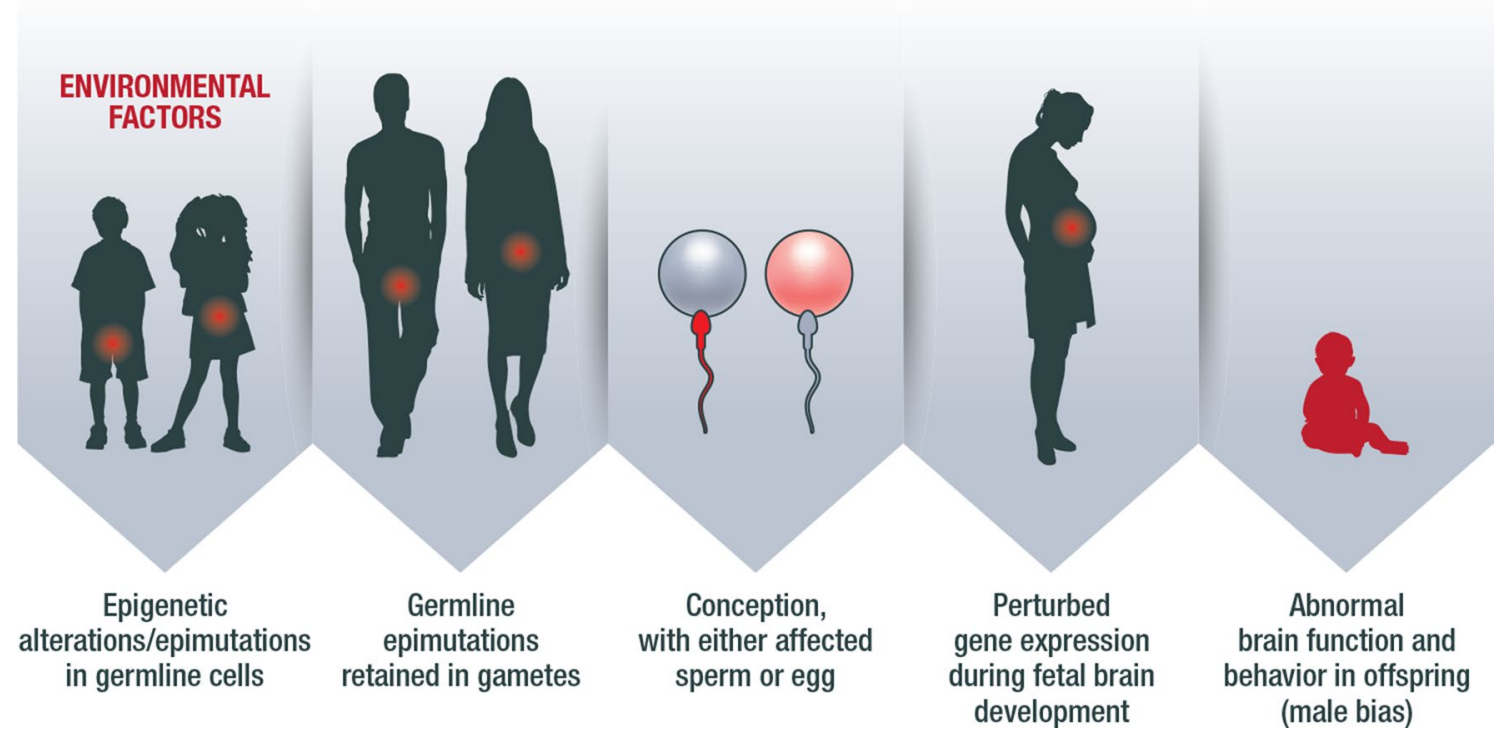

Fig. 1 Conceptual Diagram of Non-Genetic Inheritance of Autism. The diagram illustrates a general overview of how non-genetic inheritance might occur in a case of autism. As an example, an exposure to a toxicant (e.g., anesthetic gas or EDC, as discussed in this paper) could cause epimutation in the germline (in this example, the pool of spermatogonial stem cells in the male, or the pool of oocytes in the female), at genes related to brain development. This then leads to

\section{The Missing Heritability of ASD}

Our proposal goes straight to the question of the missing heritability of ASD. ASD is a broad category term that encompasses neurodevelopmental disorders of mostly unknown etiology that are characterized by impairments in social-communication, sensory dysfunction, the presence of restrictive interests and repetitive behaviors, and varying degrees of intellectual and adaptive disability (Lord et al., 2020). While there is no single pathophysiology of autism, studies point to dysregulation of genes during fetal and early life brain development, affecting cell proliferation, differentiation, neurogenesis, and migration, resulting in atypical patterning in the cerebral cortex, among other pathologies (Courchesne et al., 2019). Perturbed transcriptional pathways are seen broadly in autism cases, both in studies based on peripheral tissues and post-mortem autism brains (Gazestani et al., 2019; Gupta et al., 2014; Quesnel-Vallières et al., 2019; Voineagu et al., 2011). The transcriptional dysregulation of autism seems to occur notwithstanding the absence of any detected genetic mutations.

Epidemiological studies have yielded puzzling findings. In what seems like an irreconcilable paradox, the prevalence of autism has been steadily increasing (Boyle et al., 2011; Maenner et al., 2020; Nevison, 2014; Schendel \&
DNA methylation abnormalities in the mature sperm or ovum. Upon the conception, the pattern is retained, perturbing gene expression and the normal process of brain development in the fetus and young child. The offspring exhibits a phenotype of abnormal neurodevelopment and behaviors. This figure features childhood exposures as an example, but a similar phenomenon may occur in other periods as well

Thorsteinsson, 2018), reaching an estimated 1 in 54 U.S. children according to the Centers for Disease Control (Maenner et al., 2020), while at the same time studies repeatedly demonstrate its strong heritability. This heritability, generally seen to be approximately $50-80 \%$, has been observed in twin studies (Castelbaum et al., 2020; Sandin et al., 2017; Tick et al., 2016), in large national cohorts (Colvert et al., 2015; Sandin et al., 2014), and across populations (Bai et al., 2019). In contrast, there is generally weak evidence for prenatal or "maternal" factors broadly influencing risk (Bai et al., 2019), although certain environmental factors such as maternal valproate intake, maternal immune activation, and adverse perinatal events such as preterm birth and neonatal hypoxia can increase risk (Bölte et al., 2019; Lord et al., 2020). In addition, autism is also known to have a high recurrence risk among siblings, estimated to be $6.1 \%$ to $18.7 \%$ (Palmer et al., 2017).

Autism's strong heritability and recurrence rate, in addition to its basis in transcriptional dysfunction in brain development, has led many in the field to presume the disorder must be genetic in origin, inspiring a "genetics first" research orientation (e.g., The Simons Vip Consortium, 2012) and a general assumption that a "genetic architecture" of autism will be identified (e.g., Pereanu et al., 2018). But there are many reasons for skepticism regarding the genetics-only view of ASD's heritability. 
First, despite massive investment in genetics research, genetic mutations are seen to contribute to only about $10-20 \%$ of cases, with most of this genetic risk stemming from de novo germline mutations (Lord et al., 2020; Pugsley et al., 2021), and with many, perhaps $10 \%$, of the cases being rare syndromes involving multiple physiological and developmental pathologies extending beyond autism features (Zafeiriou et al., 2013). There is insufficient evidence to establish ASD specificity of any so-called "autism genes" (Myers et al., 2020), and potentially relevant genetic mutations, even when identified, often feature variable penetrance that may not result in an autism phenotype (De Rubeis \& Buxbaum, 2015; Lord et al., 2020). Consistent with the observation that only about $10 \%$ of autism cases without syndromic features have a known genetic origin, a recent study conducted by the Simons Foundation for Autism Research Initiative identified genetic factors recognized to be causes or significant contributors to ASD in only $10.4 \%$ of cases that lacked a previous genetic diagnosis, while also identifying variants that are possibly associated with ASD in an additional 3.4\% of families (Feliciano et al., 2019).

A role for common and normally harmless single-nucleotide polymorphisms acting additively is often speculated to exist, but despite much research regarding a possible role for common variants in explaining autism's heritability, efforts to actually locate these variants have resulted in very weak explanatory power (Grove et al., 2019). A recent review and re-evaluation of genome-wide association studies found that almost no autism risk could be predicted accurately from single-nucleotide polymorphisms, and the authors cautioned that while twin studies tend to find strong heritability, unexamined epigenetic effects should be considered as playing a role (Patron et al., 2019). Furthermore, autism is associated with strong selective pressures against transmission, and reduced fecundity (Power et al., 2013; Pugsley et al., 2021), an expectation at odds with the steadily increasing rates of diagnosed autism.

Many studies have demonstrated an association between advanced paternal age and autism risk (Bölte et al., 2019), and to a lesser degree, advanced maternal age as well (Lord et al., 2020), both of which implicate aging germ cells. However, a father's age-related germline mutations alone are unlikely to explain a significant portion of the increased risk for offspring autism (Gratten et al., 2016).

Studies using the full complement of genetic toolboxes have been unable to explain many other patterns seen in autism. While males are affected more often than females, at a ratio of about 4 to 1 (Fombonne, 2009; Maenner et al., 2020), a genetics-based explanation has not yet emerged. The high recurrence risk among siblings has yet to be explained by genetic studies. Notably, having a sibling with autism is the single strongest predictor of autism risk, stronger than any prenatal exposure or other known risk factor (Lord et al., 2020). Yet there is an unexplained genetic discordance among siblings who share an ASD diagnosis-in sibling pairs with ASD who carry rare autismrelated mutations, fewer than one-third share those mutations (Yuen et al., 2015). Even in the relatively rare cases when a genetic diagnosis can be made, only a very small fraction of cases has implications for predicting risk in siblings (D'Abate et al., 2019).

In this commentary we offer a counterpoint to the conventional thinking about the roots of autism and suggest that the disorder's etiology, heritability, sibling recurrence risk, increasing prevalence, neurobiology, heterogeneity and even its perplexing sex bias may at least in part be explained by the germline exposure history of parents and ancestors. This invokes the possibility that a toxicant-disturbed pool of parental germ cells (as opposed to, for example, harmless common genetic variants acting additively) should be the chief concern for autism causation research. To this end, we discuss (1) germ cell development and periods of vulnerability; (2) evidence for this germline disruption paradigm from both mammalian models and human studies; and (3) implications for future research.

\section{A Primer on Vulnerabilities of the Germ Cell Epigenome and Genome}

Because autism research has largely lacked experience with the biological complexity and dynamism of human germline and its multifaceted heritable contents, we offer a brief primer on germ cell biology and how the associated epigenetic processes can result in an altered transcriptional landscape, leading to abnormal gene expression.

Prior to a successful conception and subsequent birth of a baby, germ cells undergo a lengthy process of gametogenesis to produce mature sperm or oocytes (Larose et al., 2019): depending on the age of the parents at conception, precursor cells to the mature sperm or egg could have spent anywhere from approximately 14 to 50 years in the gonads. While exogenous factors disrupting replication and recombination during meiosis may increase the risk for de novo mutagenesis (DeMarini, 2012), these factors can also perturb epigenetic and other non-genetic elements, including structural packaging of proteins, histone modifications, DNA methylation, coding and noncoding RNAs, and other cellular denizens such as mitochondria in the oocyte (Lempradl, 2020; Perera et al., 2020; Sales et al., 2017; Yeshurun \& Hannan, 2019). Although toxicological paradigms tend to rely on the biological idea that "life starts at conception," this is misleading from a molecular point of view, as the elements of the heritable program are dynamically synthesized in the gametes over many years before that moment. 
The male and female germ cells initially develop in the same fashion. The diploid primordial germ cells (PGCs), the precursors of all germ cells, are first specified from the embryonic epiblast approximately 2-3 weeks after fertilization in humans. As the PGCs proliferate mitotically and migrate to the genital ridge, the precursor of the fetal gonads, they shed their former somatic epiblast identity as their DNA methylation is largely stripped away, from approximately $80 \%$ of the $\mathrm{CpG}$ dinucleotides methylated to approximately $5 \%$ in week nine (Tang et al., 2015). The period of low DNA methylation and reprogramming in the early germ cell may represent an exquisite window of susceptibility to toxicants due to the unprotected nature of the genomic DNA. While the nature of this susceptibility is not well understood, many toxicants such as endocrine disrupting chemicals (EDCs) are able to bind to various nuclear hormone receptors, which are transcription factors (TFs), and may elicit changes in transcription and occupancy of other TFs at enhancers and promoters (Martini et al., 2020). Following demethylation, the germ cells are remethylated in a sex-specific manner, as discussed below. Loss and acquisition of DNA methylation, including acquisition of genomic imprints that are specific to either sperm or egg, are necessary for the proper development of the future offspring, since abnormal methylation at imprinted genes can disturb gene expression, causing disorders such as neurodevelopmental impairment (SanMiguel \& Bartolomei, 2018). For example, improper methylation of a single allele can result in imprinting disorders such as Prader-Willi Syndrome and Angelman Syndrome (Buiting, 2010). Another example is Rett syndrome, which is caused by deficiencies in MECP2 (an X-chromosome gene) and is associated with abnormal methylation in imprinted and autism candidate genes (Samaco et al., 2005). Apart from imprinted genes, TFs bound to specific sites in the sperm and oocyte genomes remain bound to the same sites in the embryo after fertilization (Jung et al., 2019). The altered patterns of TFs occupancy in germ cells could result in changes in gene expression when the embryo starts transcribing at the 2-cell stage.

\section{Considerations for Male Germline Development}

The reprogramming of the male germline has been studied in greater detail than that of the female. In the male fetus, prospermatogonia undergo mitotic proliferation until entering mitotic arrest during the second trimester (Kurimoto \& Saitou, 2019; Phillips et al., 2010). As directed by molecular signals coming from gonadal cells, male germ cells start DNA re-methylation by week 19 and this process is completed before birth (Wen \& Tang, 2019). Shortly after birth, diploid prespermatogonia differentiate into type A spermatogonia, which resume mitosis at age 5-7 years and begin meiosis at puberty. Spermatogonial stem cells (SSCs) serve as the source for continuous production of mature sperm in adulthood (Neto et al., 2016). Damage to the genome or epigenome of SSCs, if unrepaired, will impact the quality of the final mature sperm derived from these cells. The SSCs are not exempt from external influence; rather, they communicate with the surrounding somatic cells (Sertoli cells) through gap junctions, endocytosis and extracellular vesicles, receiving nutrients, small non-coding RNAs (sncRNAs), proteins, metabolites, hormones, and other signaling molecules (Bline et al., 2020). The Sertoli cell barrier (also known as the blood-testis barrier) does not protect the Sertoli cells or SSCs from toxicants, but rather helps to protect the meiotic (spermatocytes) and haploid (spermatids) male germ cells, particularly from immunological response. Also, it appears this barrier does not exist at birth, infancy, or youth; it develops in the early phase of puberty, around 11 to 13 years of age (Mruk \& Cheng, 2015).

During spermiogenesis, the final stage of spermatogenesis, haploid spermatids undergo profound changes in both the composition and the compaction state of their nuclear chromatin. When round spermatids differentiate into elongating spermatids, histones are first replaced by transition proteins, and then by protamines, which condense the chromatin into the minute head of the spermatozoa while also offering protection of the paternal genome from potential damage caused by adverse factors (e.g., free radicals) (Wouters-Tyrou et al., 1998). However, about 5-10\% of histones persist in human sperm, including within promoter regions of genes enriched for developmental, neuronal and metabolic pathways (Lempradl, 2020). Therefore, these retained histones and their covalent modifications, in combination with DNA methylation, are, in principle, candidates to carry epigenetic information between generations (Kremsky \& Corces, 2020; Martini et al., 2020).

\section{Considerations for Female Germline Development}

Primordial germ cells, once arrived at the female genital ridge, become oogonia, which then multiply themselves via mitosis before entering meiosis between week 10 to 20 (Kurimoto \& Saitou, 2019). Soon after the initiation of meiosis, oocytes become arrested at the diplotene stage of the first meiotic prophase in the third trimester (Sanchez \& Smitz, 2012). Unlike male germ cells, the female germ cells remain globally demethylated for a lengthy period of time, until puberty, when remethylation occurs during the course of folliculogenesis. While $\mathrm{CpG}$ methylation is largely established in oocytes of the germinal vesicle stage, nonCpG DNA methylation continues to accumulate as oocytes mature into metaphase II (Yu et al., 2017). Overall, the 
oocyte DNA methylation patterns are distinct from those in sperm and somatic cells.

Similar to the male germ cells, the oocytes engage in continuous interactions with their somatic support cells, namely the granulosa cells, which provide nutrients, sncRNAs, proteins, metabolites, hormones, and other signaling molecules (Bline et al., 2020). Although there exists a blood-follicle barrier in the ovary, it is not ironclad, and chemicals that can pass the germ cell barrier include lipid-soluble compounds and the PPAR $\gamma$ agonist rosiglitazone (Janesick \& Blumberg, 2016). Studies have shown, for example, that anesthetic chemicals, which are lipid-soluble, are retained in follicular fluid following patient anesthesia (Christiaens et al., 1999), that excessive fluoride damaged oocytes in a mouse model (Wang et al., 2017), and that the halogenated anesthetic gas isoflurane resulted in a reduced number of developing follicles and an increased number of atretic follicles in mice (Tang et al., 2020). Around 300,000 oocytes remain at the start of puberty and there is a continued loss of about 1,000 follicles per month that accelerates with age, and reductions in the ovarian reserve are permanent, as female germ cells cannot be replaced (Orsi et al., 2014). Data from experimental animal models and epidemiological studies indicate that exogenous chemicals can contribute to reduction in the ovarian reserve (Ge et al., 2019).

\section{Pre-implantation Reprogramming}

One challenge to the idea of environmental exposures that affect the epigenome of the germline having any significant impact on the subsequent offspring is the wave of epigenetic reprogramming that takes place in the preimplantation embryo, which erases much of the epigenetic information, including histone modifications and DNA methylation which had been established in the egg and sperm during gametogenesis. This process, while robust, is incomplete as thousands of regions escape reprogramming and imprinted sites remain protected from reprogramming events (Seisenberger et al., 2013). Some loci associated with metabolic and neurological disorders are resistant to DNA demethylation, revealing potential for intergenerational epigenetic inheritance that may have phenotypic consequences (Tang et al., 2015). Therefore, alterations in DNA methylation induced by environmental factors during the course of gametogenesis may be retained if they are present at genomic sites that resist reprograming after fertilization (Schrott \& Murphy, 2020). However, even sites that become demethylated in the embryo may be able to maintain the memory of their germline methylated state if bound TFs in the gametes help guide the remethylation process in the post-implantation embryo (Kremsky \& Corces, 2020). In addition to chromatin-based epigenetic content being passed directly from the gametes to the zygote, there is also the possibility that non-coding RNAs expressed in the germline can provide a source of heritable information between generations (Gapp et al., 2020).

\section{De Novo Germline Mutation}

Although we focus here on the epigenome, it is also possible that toxicants can act as germline mutagens, perhaps accounting for de novo germline mutations as well as somatic mosaic mutations in early embryonic development that correlate with ASD phenotypes (Pugsley et al., 2021). With respect to de novo germline mutagenesis, germ cells generally have a strong ability to cope with DNA damage (García-Rodríguez et al., 2018), but aging primary oocytes may exhibit a decreasing ability to repair DNA damage during the lengthy postnatal period of meiotic arrest (Myers \& Hutt, 2013). Mature spermatozoa have a limited capacity to perform DNA repair and are unable to complete apoptosis, which can result in the retention of spermatozoa with damaged and/or fragmented DNA (García-Rodríguez et al., 2018). Accumulated DNA damage can result in genetic abnormalities in the offspring (Marchetti \& Wyrobek, 2005). In addition, destabilizing germline insults such as benzo(a) pyrene, a mutagenetic component of tobacco smoke and air pollution, should be considered as potential factors that raise risk for somatic mosaicism in the offspring (Beal et al., 2019; Godschalk et al., 2015).

\section{Evidence of Germ Cell Alterations Caused by Exogenous Factors in Mammalian Models and Human Studies}

We will briefly discuss four categories of substances for which germline exposure has been linked to abnormal brain development and/or behavior in offspring: halogenated anesthetic gases; hormone-disrupting exposures; products related to smoking; and valproic acid. This is not intended as an exhaustive list, but merely to illustrate the principle with actual exposures that are common in the human population and that to some extent have been investigated for heritable impacts on offspring neurodevelopment.

\section{Halogenated General Anesthetic Gases}

Based on studies to date, the toxicants that are perhaps of paramount concern are halogenated anesthetic gases. The first of these gases, halothane, was introduced into practice in 1956, followed by many others including enflurane (1972), isoflurane (1981), desflurane (1992), and sevoflurane (1995) (Whalen et al., 2005). The rate of surgical procedures in the U.S. has been increasing annually. In 2006, an estimated 53.3 million surgical and nonsurgical procedures 
were performed in U.S. ambulatory surgery centers, and in 2010, 51.4 million inpatient procedures were performed in nonfederal hospitals in the U.S. (Forum, 2017). The number of surgeries performed globally has rapidly increased, from 226.4 million in 2004 to 312.9 million in 2012, according to World Health Organization estimates (Weiser et al., 2016). The most commonly used inhaled anesthetics in these procedures are nitrous oxide and the halogenated gases, which are typically administered in combination with intravenous anesthetic agents such as midazolam or propofol (Clar et al., 2021).

The halogenated anesthetic agents commonly employed in surgical procedures are small, potent, lipophilic molecules that diffuse through vessel-rich tissues, including the gonads, with the clinical purpose to interrupt nerve signals and induce a global suppression of the nervous system. They may be used in unusually high concentrations in young children owing the immaturity of their GABAergic system (Li et al., 2019). Anesthetic gases can cause significant DNA damage (Schifilliti et al., 2011), changes in gene expression, and epigenetic alterations (Martynyuk et al., 2020; Wang et al., 2021), in both exposed somatic and germ cells (Escher \& Ford, 2020; Kaymak et al., 2012; Martynyuk et al., 2020; Wang et al., 2021). The damage caused by the gases also manifests in morphological and functional impairments in sperm (Coate et al., 1979; Land et al., 1981; Tang et al., 2020; Wang et al., 2008). The gases are also widely observed to act as steroid hormone disruptors, inducing dysfunction in the gonadal tissues and cells, with adverse impacts on germ cell integrity (Arena \& Pereira, 2002; Kaya et al., 2013; Xu et al., 2012).

Studies in rodent models have repeatedly demonstrated that germline exposure to halogenated anesthetic gases can exert adverse brain and neurobehavioral outcomes in liveborn progeny. The first of these dates back to 1981, a small study finding maternal line F2 generation of halothaneexposed gestating F0 female mice to be "significantly slower than control mice throughout the training" on all days of testing and all configurations of a maze test. Specifically, in a maze test used to assess learning, control mice made significant progress in all maze settings by the third training period. In contrast, F2 mice, born to the F1 females exposed to halothane in utero took until the seventh training period to learn the maze. The authors concluded that the impaired learning in the F2 "suggests that the anesthetic agent may have caused a genetic aberration" in the exposed mothers' fetal eggs (Chalon et al., 1981). In a 1984 paper, the same lab reported that enflurane caused impaired learning function in the generation born of the exposed germ cells, this time later-stage sperm instead of early-stage eggs (Tang et al., 1984). The researchers remarked that it "seems likely that spermatogenetic changes, caused by enflurane, are associated with genetic alterations" that affected the pups' brain development. After these papers raised the specter of potential adverse heritable impacts of general anesthesia, this important question for public health seemed to fall into the abyss, and more than three decades passed before another paper was published on this topic.

In the past few years several studies have revisited this question and have reached similar conclusions, while adding the dimension of implicating epigenetic mechanisms. In the first of these studies, sub-clinical concentrations of sevoflurane ( $2.1 \%$ sevoflurane for $6 \mathrm{~h})$ were administered to male and female neonate rat pups and the directly exposed $\mathrm{F} 0$ animals and their $\mathrm{F} 1$ progeny were examined (Ju et al., 2018). Using the elevated plus maze and the Morris water maze tests, it was found that the F0 and F1 male animals exhibit abnormal behaviors in both tests, indicating increase in anxiety and impairment in spatial memory. These behavioral abnormalities were associated with changes in gene expression of the potassium chloride cotransporter 2 ( Kcc2). $K c c 2$ expression is reduced by $20-40 \%$ in the hypothalamus and less than $20 \%$ in the hippocampus of F0 and F1 male animals compared to unexposed controls (Ju et al., 2018). DNA methylation in the promoter of the $K c c 2$ gene was examined in sperm of F0 males and hypothalamus and hippocampus of $\mathrm{F} 1$ males, and found to increase significantly in the six $\mathrm{CpG}$ sites examined after sevoflurane exposure. These data suggest that the down-regulation of $K c c 2$ gene expression and increased promoter $\mathrm{CpG}$ methylation in the $\mathrm{F} 1$ hypothalamus is associated with the increased in $\mathrm{Kcc} 2$ promoter CpG methylation of the F0 sperm. $K c c 2$ is a central nervous system (CNS) neuron-specific chloride potassium symporter localized at excitatory synapses that is essential for synaptic inhibitions, synaptic spin morphogenesis and neuroplasticity. Mutations or changes in $K c c 2$ expression are involved in many neurological diseases including brain trauma, epilepsies, autism and schizophrenia (Agez et al., 2017). These findings suggest that sevoflurane could induce a nongenetic effect in early-stage germ cells, causing some sex-specific brain and behavioral abnormalities in the next generation, even when used at low concentrations. An editorial accompanying the paper reporting these results noted that general anesthetics may modulate developmental neuroplasticity in the next generation via changes in gene expression and DNA methylation (Vutskits et al., 2018).

Studies by the same group found that expression of DNA methyltransferase $3 \mathrm{a}$ and $3 \mathrm{~b}$ (Dnmt $3 a$ and Dnmt $3 b$, enzymes that catalyze the transfer of a methyl group to DNA) in the hypothalamus of $\mathrm{F} 1$ animals was increased by more than $40 \%$ compared to unexposed control males (Xu et al., 2020). When the animals were treated with Decitabine, a methyltransferase inhibitor, prior to sevoflurane exposure, the expression of Dnmt $3 a$, Dnmt $3 b$, and $K c c 2$ in the hypothalamus of F1 animals were similar as unexposed control animals and the animals exhibit normal behaviors. These 
data suggest that DNA methyltransferase activity might be involved in the response to sevoflurane exposure at the $K c c 2$ locus. In the future, it would be interesting to perform genome-wide analyses of changes in gene expression and DNA methylation in this system.

In addition, administration of sevoflurane to young adult rats (with more mature germ cells) resulted in similar, though not identical, abnormalities in parental germ cells and in male offspring of exposed sires and dams (Ju et al., 2019). Notably, the lab's experiments suggested that compared to the somatic cells, the germ cells are more sensitive to the deleterious effects of sevoflurane, raising the possibility that male offspring may be affected even when the anesthesia level/duration is insufficient to induce significant abnormalities in exposed parents (Martynyuk et al., 2020).

Another lab recently performed experiments with some similar aims but looking only at the offspring brain as an endpoint rather than the parental germ cells or offspring behaviors. After exposing neonatal female rats to sevoflurane, they bred the females and found their F1 offspring's brains exhibited epigenetic abnormalities, including reduced DNA methylation in hippocampal neurons and upregulation of Arc and Junb mRNA expression in F1 males born to F0 exposed females, an effect linked to functional decline in learning and memory. This effect was sexually dimorphic, again only noted in the F1 male progeny (Chastain-Potts et al., 2020).

A recent study from another lab demonstrated the molecular basis for neurodevelopmental pathology in offspring of sperm of F1 sons of pregnant mice exposed to sevoflurane (Wang et al., 2021). Gestating F0 mice were exposed at day E12.5 of $\mathrm{F} 1$ embryonic development for $2 \mathrm{~h}$, as this is the time when the germline of the exposed fetus is fully demethylated and may be more susceptible to environmental exposures. Adverse behavioral defects were observed in more than $38 \%$ of the directly exposed F1 males, including sociability deficits and increased anxiety as measured by the three-chamber sociability test, bedding shredding and marble burying tests. By outcrossing the F1 males to unexposed females for two generations, sevoflurane was found to have both "intergenerational" (F2 derived from exposed germline) and "transgenerational" (F3 derived from germline never exposed to sevoflurane) actions. In fact, $44-47 \%$ of the $\mathrm{F} 2$ and $\mathrm{F} 3$ showed the same behavioral problems as the $\mathrm{F} 1$ males (females were not tested). Based on preliminary data from one of our labs (VGC), these behavioral phenotypes correlate with reduced neonatal brain size and weight. However, the brain size and weight differences were not apparent in the mature adult mice. The inter- and transgenerational inheritance through the male germ cells was confirmed by Assay for Transposase-Accessible Chromatin sequencing (ATAC-seq) experiments in sperm of the F1 and F2 generations, which showed a dramatic recruitment of TFs to enhancer sequences of genes found to be associated with
ASD, including Arid1b, Ntrk2, and Stmn2 (Wang et al., 2021). These results and the ones described above point to a correlation between exposure of laboratory animals to sevoflurane, alterations of the transcriptional landscape in the germline, changes in progeny's neural cell epigenomes, and the development of behavioral phenotypes similar to those displayed by humans diagnosed with autism. Therefore, evidence obtained in mouse models by independent laboratories suggest that sevoflurane, one of the most commonly utilized GA agents in surgery, could led to heritable alterations in the epigenome of the germ cells and brain, through changes in DNA modifications, gene expression and transcription factor occupancy.

In human cohorts, research on germ cell impacts of general anesthesia has been surprisingly sparse, but intriguingly two studies point to significant molecular vulnerabilities. In terms of the epigenome, one study examining obesity and bariatric surgery found significant changes in spermatozoa DNA methylation in 1509 genes approximately one week after surgery, with persistent effects in 1004 genes and $1116 \mathrm{CpG}$ positions a year later (Donkin et al., 2016). Though the authors attributed these changes to weight loss and nutritional factors, the sudden nature of the effects point to the anesthesia as possibly the more salient exposure (Martynyuk et al., 2020). A 2012 study on DNA damage in sperm in vitro after exposure to various concentrations of halothane, isoflurane, desflurane and sevoflurane was conducted by the classic DNA damage "comet" assay (Kaymak et al., 2012), which assesses DNA damage via single cell gel electrophoresis (Azqueta \& Collins, 2013). The genotoxic effect was dose-dependent for isoflurane and sevoflurane, and halothane was most strongly genotoxic, but this effect was not dose dependent. No genotoxic effect was observed for desflurane. The study was preliminary in nature, however, offering no data on repeated exposures or different durations (Kaymak et al., 2012). It is also worth noting that a recent epidemiological study on a large Danish cohort found a twofold higher autism risk in offspring of parents who had been born very preterm, that is, less than 32 weeks of gestation (Xiao et al., 2021). Although this was not part of the study's evaluation, it is well known that premature infants, and in particular very preterm infants, undergo sharply higher rates of early life drug exposure, including anesthesia for surgery, opiates, oxygen, and corticosteroids (Smrcek et al., 2005).

Taken together, the studies offer evidence that agents of general anesthesia can induce molecular changes in germline, changing transcription of key brain development genes and inducing adverse neurodevelopmental outcomes in progeny, particularly males. 


\section{Synthetic Steroids, Endocrine-Disrupting Chemicals and Endocrine Disease}

In recent decades, humans have been increasingly treated with synthetic hormone drugs and exposed to many environmental substances that act as EDCs (Diamanti-Kandarakis et al., 2009). Most of these substances affect molecular signaling through the superfamily of nuclear receptors, which act as DNA-binding TFs with powerful capabilities of modifying the epigenetic landscape and gene expression programs (Ozgyin et al., 2015). Numerous studies support the hypothesis that alterations in endocrine systems influence the epigenetic information of the germline which may lead to neurodevelopmental and behavioral abnormalities in subsequent generations.

Several studies have investigated heritable impacts of synthetic steroid drugs. In a guinea pig model, F0 gestational treatment with a clinically relevant dose of the synthetic glucocorticoid betamethasone led to abnormalities in the F2 generation, including modified physiology of the hypothalamic-pituitary-adrenal (HPA) axis and increased locomotor activity in a novel location (Moisiadis et al., 2017). In a mouse study, elevated paternal glucocorticoid exposure altered the profile of small noncoding RNA profile in sperm and resulted in increased anxiety-like behavior in next-generation (F1) males, but decreased the same behaviors in F2 male and female offspring. In F2 males only there was evidence of enhanced depression-like behaviors (Short et al., 2016). In humans, grandchildren of pregnant women administered the notorious synthetic estrogen diethylstilbestrol (DES) (data from descendants of over 47,000 DES-treated women) exhibit significantly increased risk for ADHD through the maternal line (Kioumourtzoglou et al., 2018).

In addition to endocrine alterations due to exogenous administration of drugs, aberrant status of endogenous hormones may also impact germline and influence neurological phenotypes in subsequent generations. This may occur due to chronic stress, which elevates circulating levels of glucocorticoids. Neonatal, juvenile and adult stress may change the profile of microRNAs, a category of sncRNAs, in the sperm and lead to aberrant programming of the HPA axis and to anxiety and other neurological phenotypes in subsequent generations (Dickson et al., 2018; Gapp et al., 2014; Jawaid et al., 2018; Manners et al., 2019; Morgan \& Bale, 2011; Rodgers et al., 2013, 2015; Saavedra-Rodríguez \& Feig, 2013). Alterations in thyroid hormone, which occurs in women with thyroid disease, can also cause intergenerational effects, affecting neuroendocrine function (Anselmo et al., 2019; Bakke et al., 1977). Furthermore, sperm epigenetic information is altered in a mouse model of developmental overexposure to thyroid hormone (Martinez et al., 2020). This exposure causes hypomethylation in the promoter of genes involved in brain development that are also implicated in ASD and other neurological disorders. F2 generation descendants of exposed male and female mice exhibit altered neonatal brain gene expression programs and abnormal behaviors (Martinez et al., 2020).

Studies involving environmental EDCs have also found links between germline exposure and abnormal neurobehavioral outcomes in the offspring. Exposure of F1 fetal rats to the androgenic fungicide vinclozolin or to polychlorinated biphenyls, which mimic the structure of thyroid hormones, led to socio-sexual behavioral abnormalities in the F2 progeny, with males most affected (Krishnan et al., 2018, 2019). This was associated with abnormal expression of steroid hormone receptors (estrogen receptor $\alpha$, androgen and progesterone receptors) in the medial preoptic area and ventromedial nucleus of the hypothalamus (Krishnan et al., 2018, 2019). Several studies have examined the effects of bisphenol A (BPA), a compound with estrogenic properties, on social behaviors in mice of the first and subsequent generations (Goldsby et al., 2017; Wolstenholme et al., 2012, 2019). Mice exposed to BPA in utero exhibited reduced social interest compared to control mice, but sociability was increased in subsequent generations (Wolstenholme et al., 2012). The brains of BPA-exposed fetal mice exhibited reduced expression of oxytocin and vasopressin, critical neuropeptides controlling social behaviors in mice and humans which have been implicated in ASD and schizophrenia. The brain expression of vasopressin and estrogen receptor $\alpha$, which regulates the expression of oxytocin (Young et al., 1998) and vasopressin (Scordalakes \& Rissman, 2004) was also reduced in BPA mice (Wolstenholme et al., 2012). The decrease in vasopressin expression persisted until the F3 generation in the BPA lineage, which also exhibited severe deficits in social recognition and the expression of postsynaptic density genes (Wolstenholme et al., 2019). Interestingly, BPA-line F3 generation mice also exhibited marked abnormalities in the expression of imprinted genes, especially the maternally expressed gene Meg3 (Drobna et al., 2018). It is worth noting that these changes in gene expression were found in areas related to the sexual differentiation of the brain, including the lateral septum, amygdala, preoptic area, hypothalamus and bed nucleus of the stria terminalis (Drobna et al., 2018; Goldsby et al., 2017).

Mechanistically, EDCs may behave similarly to the endogenous hormones that they mimic and bind to or interfere with the binding of endogenous hormone receptors (e.g., steroid receptors) or other binding proteins involved in hormone physiology and action, ultimately impacting receptor chromatin modification and transcriptional functions (Lakshmanan \& Shaheer, 2020; Martini et al., 2020). Directly, by binding to hormone receptors, or indirectly, by changing recruitment patterns of TFs, including Ctcf, EDCs could reprogram the germline at different stages of development (Fiorito et al., 2016). DNA-bound TFs could then modify 
accessibility of epigenetic modifiers to specific genomic loci. For example, ATAC-seq experiments carried out with sperm from the F1 through F6 progeny of mice exposed to BPA in utero reveal disruptions at binding sites for Ctcf, Foxa1, Esr1 and $\operatorname{Ar}$ (Jung et al., 2020). The sperm disruptions persist (or lead to subsequent disruptions) after fertilization in somatic cells of the post-implantation embryo, affecting cell differentiation and development in the next generation, eliciting abnormal phenotypes in the adult organism. These abnormal patterns of transcription may affect genes critical for the development of neurological and endocrine functions in the offspring (Martini et al., 2020). This has been shown to be the case for BPA-induced alterations in sperm in the binding of Ctcf to an enhancer of the Fto gene. These alterations are maintained in the hypothalamus and affect the differentiation of POMC and AgRP neurons in the arcuate nucleus, leading to increased food consumption and obesity (Jung et al., 2020).

Given the dramatic surge in the medical use of synthetic hormones and environmental exposure to EDCs over the course of the past six decades, it is possible that some of these exposures are altering the transcriptional program of germline, conferring risk for dysregulated brain development and abnormal behaviors.

\section{Tobacco and Related Products}

Whether germline exposure to tobacco, its metabolites, or related products can influence autism risk may depend on timing and dose. While maternal smoking either before or during pregnancy may be associated with a variety of risks to the fetus, evidence for an increase in autism risk is low (Lee et al., 2012; Rosen et al., 2015), with perhaps only a slightly elevated risk when the mother was a heavy smoker (von Ehrenstein et al., 2020). However, in contrast to earlier studies, a recent epidemiological study based on two large cohorts in Korea found paternal smoking correlated to an increased likelihood of ASD in offspring. The authors concluded that elimination of paternal smoking might reduce the risk of having a child with ASD by as much as 11-14\% (Kim et al., 2021). Fetal germline impacts were the subject of study in the Avon Longitudinal Study of Parents and Children (ALSPAC) cohort, which linked grandmaternal smoking in pregnancy with an increased risk for autism traits and diagnosed autism in grand-offspring through the maternal line (Golding et al., 2017), though it lacked data on dose effects.

Both mutagenic and epimutagenic factors may be at play. Paternal smoking affects the mutation rates in sperm (Axelsson et al., 2018; Haervig et al., 2020), for example by increasing DNA adducts caused by a metabolite of benzo(a) pyrene $(\mathrm{BaP})$, a known carcinogen and main component of tobacco smoke (Beal et al., 2019; Laubenthal et al., 2012;
Linschooten et al., 2013). Studies in rodents demonstrate that ingestion of nicotine by gestating dams increased risk for ADHD-like behaviors in the F2 generation (Buck et al., 2019; Zhu et al., 2014), with epigenetic mechanisms in the exposed germline being implicated (Buck et al., 2019). More recently, a study showed that mouse sires exposed to nicotine and saccharin, a mixture common in vaping products, produced male (females were not examined) offspring with elevated activity and reduced spatial memory (McCarthy et al., 2020). Both nicotine and saccharine exposure produces significant changes in DNA methylation at promoter regions of dopamine receptor genes in spermatozoa, suggesting that epigenetic modification of sperm DNA may link the exposure to the behavioral phenotypes (McCarthy et al., 2020).

The generational effects of cannabis use have also emerged as a concern for heritable neurobehavioral effects. One study has reported alterations in DNA methylation in human sperm in men that were frequent cannabis users as compared with non-smokers (Murphy et al., 2018). A follow-up study looked at the effects of cannabis exposure on DNA methylation of the gene Disks-large associated protein 2 (DLGAP2), which is implicated in ASD (Schrott et al., 2020). This gene exhibited 17 differentially methylated CpG sites by Reduced representation bisulfite sequencing (RRBS) in the sperm of cannabis-exposed men compared to controls. In the brains of rats born to THC-exposed fathers, significant loss of methylation was detected at the same $\mathrm{CpG}$ sites in the nucleus accumbens as in the sperm of the exposed fathers, suggesting paternal exposure could alter the epigenetic profile of the offspring.

\section{Valproic Acid}

Histone deacetylase (HDAC) inhibitors are drugs commonly used to treat seizure disorders and other mental conditions that act directly on the epigenome, by inhibiting removal of the acetyl groups from lysine residues on histones, leading to the establishment of a transcriptionally silenced chromatin. Fetal exposure to the HDAC inhibitor valproic acid (VPA) induces an autism-like neurobehavioral phenotype in mice and is known to cause autism-related neurobehavioral impairment in humans (Roullet et al., 2013). Evidence from rodent models is also emerging that VPA causes neurobehavioral impacts on the next generation via an exposed germline. VPA induced epigenetic inheritance of an autism-like phenotype in mice through the paternal germline in the first and second generation (Choi et al., 2016). Similarly, paternal VPA exposure increased behavioral abnormalities in adult offspring, with increased levels of acetylated histone $\mathrm{H} 3$ in the testicular tubules of sires, but, surprisingly, decreased the levels of acetylated histone $\mathrm{H} 3$ in the brain of adult offspring (Ibi et al., 2019). In this case, the relationship between 
effects in the germline and somatic tissues would have to be indirect. In another mouse study on a fetal germline exposure to VPA, the offspring exhibited early behavioral alterations and increased expression of endogenous retroviruses (Tartaglione et al., 2019).

To our knowledge, no human study has investigated outcomes after fetal germline exposure to HDAC inhibitors. However, paternal use of antiepileptic medications (which are often HDAC inhibitors), prior to conception tend not to be associated with an increased risk of autism in offspring (Tomson et al., 2020). Earlier stage exposures remain to be investigated.

\section{Implications for Autism Research}

Here we have described how non-genetic heritable information induced in the germline by exposure to exogenous toxicants and other environmental factors could contribute to the etiology of neurodevelopmental and behavioral abnormalities, some of relevance to ASD. While the field largely focuses on genetic architecture, we instead stress the importance of an epigenetic landscape that may be perturbed by molecular events in the parental germ cells. This paradigm has many implications for future research directions.

\section{Mammalian Models}

Mammalian models can be employed to look at exposures to both male and female germline with various agents, mixtures, and intensities across the span of germ cell developmental windows. Endpoints may include impacts on germline genetics and epigenetics and neurological phenotypes in the offspring and descendants, including brain gene transcription and epigenetic profiles in brain, neuromorphology and cytoarchitecture and behavior. Agents of interest may include those reviewed above, but there may be many other factors capable of exerting intergenerational effects. In this regard, some medications given to women during pregnancy (for example, anti-nausea drugs, anti-preterm birth steroids, psychoactive drugs), especially those with known mutagenic or epigenetic properties, such as chemotherapeutic agents, should raise concern (Kaplanis et al., 2021). A similar concern applies to an increasingly long list of environmental chemicals that act as endocrine disruptors which could affect the germline directly, or indirectly via altering endogenous endocrine systems. Other exposures may derive from specific occupational hazards in subsets of the population. For example, it has been observed that maternal occupational exposure to solvents may increase the risk for ASD in the offspring (McCanlies et al., 2019).

\section{Epidemiology}

Although prospective human studies would be difficult, retrospective studies should be feasible in many available cohorts with reliable data about specific exposures (for example, surgery histories of the parents, medications dispensed to women during pregnancy, medication history of the fathers) and neurodevelopmental outcomes in offspring of the exposed germ cells. Additionally, in light of a machine-learning based study from Denmark finding that family history of multiple mental and non-mental conditions can identify more individuals at highest risk for ASD than only considering the immediate family history of ASD (Ejlskov et al., 2021), further big data approaches focusing on specific exposures such as surgery, that are associated with health conditions, warrant further investigation. While register-based studies from the Nordic countries may be the most suitable for epidemiological studies involving more than one generation, other specific cohorts in other countries may also be possible, as has already been seen with ALSPAC (Golding et al., 2017), and Nurses Health Study II (Kioumourtzoglou et al., 2018). Epidemiologic approaches for performing intergenerational associations were recently explored in McGee et al. (2020).

\section{Sex Bias of Autism}

Studies in mammalian models often show that males born of toxicant-exposed germ cells at increased risk for brain and/or neurobehavioral abnormality, as compared to females (Chastain-Potts et al., 2020; Ju et al., 2018, 2019; Krishnan et al., 2018), although the underlying mechanisms for this sex bias have not been ascertained. Given the sex steroid-like properties of many of the drugs and chemicals discussed in this paper, epigenetic programming of sex steroid target genes, including those regulating the HPA-gonadal axis and sex hormone output, may occur. This in turn may impact processes of brain maturation in a sex-specific manner, ultimately resulting in sexually dimorphic neurobehavioral outcomes. Sexual dimorphism in intergenerational effects may also be the result of altered epigenetic information affecting the $\mathrm{X}$ chromosome; due to $\mathrm{X}$ chromosome inactivation in females, cell mosaicism may result in less severe and more variable impacts. However, these and other questions remain to be investigated.

\section{Broader Autism Phenotype (BAP)}

The BAP, a collection of sub-diagnostic traits sometimes seen in parents of children with autism (Rubenstein \& Chawla, 2018) could in some cases be accounted for by 
that parent's developmental exposures, for example in utero exposure to synthetic sex steroids, or early life exposure to high doses of general anesthesia, as both exposures are associated with neurobehavioral difference and impairments (Ing et al., 2021; Reinisch \& Karow, 1977; Warner et al., 2018). Indeed, there is some early evidence that perinatal exposure to general anesthesia administered as part of a C-section, may increase risk for autism in the exposed individual (Huberman Samuel et al., 2019; Yang et al., 2021).

\section{Case Studies of Idiopathic Multiplex Families}

The autism family population represents a vast and generally untapped resource for addressing novel questions about germline exposures. In particular, parents who have strong recurrence of autism in their offspring could be questioned about their (and therefore their germ cells') exposure histories or that of their parents (Escher, 2021). While such data would be anecdotal in nature, it could contribute valuable information to generate new hypotheses about the heritable origins of autism. Similarly, the phenotypic heterogeneity of autism, seen even within families, may be explained by differences in molecular impacts within the pool of affected parental germ cells.

\section{Studies of Sperm of Exposed Males}

Considering the dramatic increase in the use of genotoxic and epigenotoxic drugs and chemicals, relatively little attention has been paid to how these exposures affect the qualities of human sperm. A small study found that DNA from the sperm of men whose children had early signs of autism shows distinct patterns of regulatory tags that could contribute to the condition (Feinberg et al., 2015). While the study did not explore paternal exposure history, it found 193 differentially methylated regions (DMRs) where the presence or absence of DNA methylation was statistically related to autism scores based on the Autism Observation Scale for Infants (AOSI) in their offspring. Interestingly, 24\% of AOSI-associated DMRs are also found in the cerebellum of autistic individuals, lending support to the idea of causal relationship between epigenetic alterations in sperm and in adult tissues. Similarly, a small study on sperm of fathers who have children with ASD observed a set of 805 DMRs in sperm that could potentially act as a biomarker for paternal offspring autism susceptibility (Garrido et al., 2021). Evaluating the genetic and epigenetic signatures in the sperm of males against the backdrop of their known environmental exposures and lifetime clinical histories may yield provocative insights currently unexamined in the literature. Unfortunately, it is relatively difficult to directly study the eggs of exposed mothers except perhaps as part of assisted reproduction procedures, and even then, harvesting procedures involve the use of exogenous hormones and anesthetics which may influence oocyte content.

\section{Critical Reevaluation of the Current Literature}

Another important undertaking, and one not requiring any clinical, experimental or epidemiological studies, would simply involve a critical reevaluation of the current autism literature to take into account this third dimension of risk. Studies warranting reevaluation include but are not limited to those involving sharply increasing prevalence across the past several decades, heritability modeling and heightened sibling risk, broader autism phenotype among family members, sex ratios among affected offspring, and even the sexspecific differential ASD clinical manifestations. Of course, the study of genetic transcriptional dysregulation of autism brains would also benefit from taking into account these non-genetic factors.

\section{Conclusion}

Despite decades of diligent effort, autism's etiology, increase in prevalence, heritability, sibling recurrence, sex bias, heterogeneity and basis in early transcriptional dysregulation remain largely unexplained. In order to accelerate progress with respect to all of these questions, we propose adding the phenomenon of germline disruption to the conventional approaches of genetics and somatic environmental exposures. Expanding our notions of pathogenesis may not only help explain many unsolved questions, it may also inform future directions for prevention, diagnosis and effective treatment.

Author Contributions JE conceived the review and wrote the manuscript. WY, EFR, H-LW, AH, and VGC contributed to writing the manuscript.

Funding The authors have no funding to declare.

\section{Declarations}

Conflict of interest The authors declare they have no conflicts of interest.

Open Access This article is licensed under a Creative Commons Attribution 4.0 International License, which permits use, sharing, adaptation, distribution and reproduction in any medium or format, as long as you give appropriate credit to the original author(s) and the source, provide a link to the Creative Commons licence, and indicate if changes were made. The images or other third party material in this article are included in the article's Creative Commons licence, unless indicated otherwise in a credit line to the material. If material is not included in the article's Creative Commons licence and your intended use is not permitted by statutory regulation or exceeds the permitted use, you will 
need to obtain permission directly from the copyright holder. To view a copy of this licence, visit http://creativecommons.org/licenses/by/4.0/.

\section{References}

Agez, M., Schultz, P., Medina, I., Baker, D. J., Burnham, M. P., Cardarelli, R. A., Conway, L. C., Garnier, K., Geschwindner, S., Gunnarsson, A., McCall, E. J., Frechard, A., Audebert, S., Deeb, T. Z., Moss, S. J., Brandon, N. J., Wang, Q., Dekker, N., \& Jawhari, A. (2017). Molecular architecture of potassium chloride co-transporter KCC2. Science and Reports, 7, 16452. https://doi.org/10. 1038/s41598-017-15739-1

Anselmo, J., Scherberg, N. H., Dumitrescu, A. M., \& Refetoff, S. (2019). Reduced sensitivity to thyroid hormone as a transgenerational epigenetic marker transmitted along the human male line. Thyroid: Official Journal of the American Thyroid Association, 29, 778-782.

Arena, A. C., \& Pereira, O. C. (2002). Neonatal inhalatory anesthetic exposure: Reproductive changes in male rats. Comparative Biochemistry and Physiology Part C: Toxicology \& Pharmacology, 133, 633-640. https://doi.org/10.1016/s1532-0456(02)00182-5

Axelsson, J., Sabra, S., Rylander, L., Rignell-Hydbom, A., Lindh, C. H., \& Giwercman, A. (2018). Association between paternal smoking at the time of pregnancy and the semen quality in sons. PLoS ONE, 13, e0207221. https://doi.org/10.1371/journal.pone. 0207221

Azqueta, A., \& Collins, A. R. (2013). The essential comet assay: A comprehensive guide to measuring DNA damage and repair. Archives of Toxicology, 87, 949-968. https://doi.org/10.1007/ s00204-013-1070-0

Bai, D., et al. (2019). Association of genetic and environmental factors with autism in a 5-country cohort. JAMA Psychiatry, 76, 1035-1043. https://doi.org/10.1001/jamapsychiatry.2019.1411

Bakke, J. L., Lawrence, N. L., Robinson, S., \& Bennett, J. (1977). Endocrine studies in the untreated $\mathrm{F} 1$ and $\mathrm{F} 2$ progeny of rats treated neonatally with thyroxine. Neonatology, 31, 71-83.

Beal, M. A., Meier, M. J., Williams, A., Rowan-Carroll, A., Gagné, R., Lindsay, S. J., Fitzgerald, T., Hurles, M. E., Marchetti, F., \& Yauk, C. L. (2019). Paternal exposure to benzo(a) pyrene induces genome-wide mutations in mouse offspring. Communications Biology, 2, 228. https://doi.org/10.1038/ s42003-019-0476-5

Bline, A. P., Le Goff, A., \& Allard, P. (2020). What is lost in the Weismann barrier? Journal of Developmental Biology. https://doi. org/10.3390/jdb8040035

Bölte, S., Girdler, S., \& Marschik, P. B. (2019). The contribution of environmental exposure to the etiology of autism spectrum disorder. Cellular and Molecular Life Sciences, 76, 1275-1297. https://doi.org/10.1007/s00018-018-2988-4

Boyle, C. A., Boulet, S., Schieve, L. A., Cohen, R. A., Blumberg, S. J., Yeargin-Allsopp, M., Visser, S., \& Kogan, M. D. (2011). Trends in the prevalence of developmental disabilities in US children, 1997-2008. Pediatrics, 127, 1034-1042. https://doi.org/10.1542/ peds.2010-2989

Buck, J. M., Sanders, K. N., Wageman, C. R., Knopik, V. S., Stitzel, J. A., \& O'Neill, H. C. (2019). Developmental nicotine exposure precipitates multigenerational maternal transmission of nicotine preference and ADHD-like behavioral, rhythmometric, neuropharmacological, and epigenetic anomalies in adolescent mice. Neuropharmacology, 149, 66-82. https://doi.org/10.1016/j.neuro pharm.2019.02.006

Buiting, K. (2010). Prader-Willi syndrome and Angelman syndrome. American Journal of Medical Genetics Part C: Seminars in
Medical Genetics, 154C, 365-376. https://doi.org/10.1002/ ajmg.c. 30273

Castelbaum, L., Sylvester, C. M., Zhang, Y., Yu, Q., \& Constantino, J. N. (2020). On the nature of monozygotic twin concordance and discordance for autistic trait severity: A quantitative analysis. Behavior Genetics, 50, 263-272. https://doi.org/10.1007/ s10519-019-09987-2

Chalon, J., Tang, C. K., Ramanathan, S., Eisner, M., Katz, R., \& Turndorf, H. (1981). Exposure to halothane and enflurane affects learning function of murine progeny. Anesthesia and Analgesia, 60, 794-797.

Chastain-Potts, S. E., Tesic, V., Tat, Q. L., Cabrera, O. H., Quillinan, N., \& Jevtovic-Todorovic, V. (2020). sevoflurane exposure results in sex-specific transgenerational upregulation of target IEGs in the subiculum. Molecular Neurobiology, 57, 11-22. https://doi. org/10.1007/s12035-019-01752-0

Choi, C. S., Gonzales, E. L., Kim, K. C., Yang, S. M., Kim, J. W., Mabunga, D. F., Cheong, J. H., Han, S. H., Bahn, G. H., \& Shin, C. Y. (2016). The transgenerational inheritance of autism-like phenotypes in mice exposed to valproic acid during pregnancy. Science and Reports, 6, 36250. https://doi.org/10.1038/srep3 6250

Christiaens, F., Janssenswillen, C., Verborgh, C., Moerman, I., Devroey, P., Van Steirteghem, A., \& Camu, F. (1999). Propofol concentrations in follicular fluid during general anaesthesia for transvaginal oocyte retrieval. Human Reproduction, 14, 345-348. https://doi.org/10.1093/humrep/14.2.345

Clar, D. T., Patel, S., \& Richards, J. R. (2021). Anesthetic Gases (Updated 2021 Apr 11). In StatPearls [Internet]. Treasure Island, FL: StatPearls Publishing. Retrieved July 13, 2021, https://www. ncbi.nlm.nih.gov/books/NBK537013/

Coate, W. B., Kapp, R. W., Jr., \& Lewis, T. R. (1979). Chronic exposure to low concentrations of halothane-nitrous oxide: Reproductive and cytogenetic effects in the rat. Anesthesiology, 50, 310-318. https://doi.org/10.1097/00000542-197904000-00006

Colvert, E., Tick, B., McEwen, F., Stewart, C., Curran, S. R., Woodhouse, E., Gillan, N., Hallett, V., Lietz, S., Garnett, T., Ronald, A., Plomin, R., Rijsdijk, F., Happe, F., \& Bolton, P. (2015). Heritability of autism spectrum disorder in a UK population-based twin sample. JAMA Psychiatry, 72, 415-423. https://doi.org/10. 1001/jamapsychiatry.2014.3028

Courchesne, E., Pramparo, T., Gazestani, V. H., Lombardo, M. V., Pierce, K., \& Lewis, N. E. (2019). The ASD living biology: From cell proliferation to clinical phenotype. Molecular Psychiatry, 24, 88-107. https://doi.org/10.1038/s41380-018-0056-y

D'Abate, L., et al. (2019). Predictive impact of rare genomic copy number variations in siblings of individuals with autism spectrum disorders. Nature Communications, 10, 5519. https://doi.org/10. 1038/s41467-019-13380-2

De Rubeis, S., \& Buxbaum, J. D. (2015). Genetics and genomics of autism spectrum disorder: Embracing complexity. Human Molecular Genetics, 24, R24-31. https://doi.org/10.1093/hmg/ddv273

Demarini, D. M. (2012). Declaring the existence of human germ-cell mutagens. Environmental and Molecular Mutagenesis, 53, 166172. https://doi.org/10.1002/em.21685

Diamanti-Kandarakis, E., Bourguignon, J. P., Giudice, L. C., Hauser, R., Prins, G. S., Soto, A. M., Zoeller, R. T., \& Gore, A. C. (2009). Endocrine-disrupting chemicals: An endocrine society scientific statement. Endocrine Reviews, 30, 293-342. https://doi.org/10. 1210/er.2009-0002

Dickson, D. A., Paulus, J. K., Mensah, V., Lem, J., Saavedra-Rodriguez, L., Gentry, A., Pagidas, K., \& Feig, L. A. (2018). Reduced levels of miRNAs 449 and 34 in sperm of mice and men exposed to early life stress. Translational Psychiatry, 8,101 . https://doi. org/10.1038/s41398-018-0146-2 
Dietz, P. M., Rose, C. E., McArthur, D., \& Maenner, M. (2020). National and state estimates of adults with autism spectrum disorder. Journal of Autism and Developmental Disorders, 50, 4258-4266. https://doi.org/10.1007/s10803-020-04494-4

Donkin, I., Versteyhe, S., Ingerslev, L. R., Qian, K., Mechta, M., Nordkap, L., Mortensen, B., Appel, E. V., Jørgensen, N., Kristiansen, V. B., Hansen, T., Workman, C. T., Zierath, J. R., \& Barrès, R. (2016). Obesity and bariatric surgery drive epigenetic variation of spermatozoa in humans. Cell Metabolism, 23, 369-378. https://doi.org/10.1016/j.cmet.2015.11.004

Drobna, Z., Henriksen, A. D., Wolstenholme, J. T., Montiel, C., Lambeth, P. S., Shang, S., Harris, E. P., Zhou, C., Flaws, J. A., Adli, M., \& Rissman, E. F. (2018). Transgenerational effects of bisphenol A on gene expression and DNA methylation of imprinted genes in brain. Endocrinology, 159, 132-144. https://doi.org/10. 1210/en.2017-00730

Ejlskov, L., Wulff, J. N., Kalkbrenner, A., Ladd-Acosta, C., Fallin, M. D., Agerbo, E., Mortensen, P. B., Lee, B. K., \& Schendel, D. (2021). Prediction of autism risk from family medical history data using machine learning: A national cohort study from Denmark. Biological Psychiatry Global Open Science. https:// doi.org/10.1016/j.bpsgos.2021.04.007

Escher, J. (2021). How family histories can inform research about germ cell exposures: The example of autism. Biology of Reproduction, 105, 767-773. https://doi.org/10.1093/biolre/ioab092

Escher, J., \& Ford, D. (2020). General anesthesia, germ cells and the missing heritability of autism: An urgent need for research. Environmental Epigenetics, 6, dvaa007. https://doi.org/10.1093/eep/ dvaa007

Feinberg, J. I., Bakulski, K. M., Jaffe, A. E., Tryggvadottir, R., Brown, S. C., Goldman, L. R., Croen, L. A., Hertz-Picciotto, I., Newschaffer, C. J., Fallin, M. D., \& Feinberg, A. P. (2015). Paternal sperm DNA methylation associated with early signs of autism risk in an autism-enriched cohort. International Journal of Epidemiology, 44, 1199-1210. https://doi.org/10.1093/ije/dyv028

Feliciano, P., Zhou, X., Astrovskaya, I., Turner, T. N., Wang, T., Brueggeman, L., Barnard, R., Hsieh, A., Snyder, L. G., Muzny, D. M., Sabo, A., Consortium, S., Gibbs, R. A., Eichler, E. E., O’Roak, B. J., Michaelson, J. J., Volfovsky, N., Shen, Y., \& Chung, W. K. (2019). Exome sequencing of 457 autism families recruited online provides evidence for autism risk genes. NPJ Genomic Medicine, 4, 19. https://doi.org/10.1038/s41525-019-0093-8

Fiorito, E., Sharma, Y., Gilfillan, S., Wang, S., Singh, S. K., Satheesh, S. V., Katika, M. R., Urbanucci, A., Thiede, B., Mills, I. G., \& Hurtado, A. (2016). CTCF modulates estrogen receptor function through specific chromatin and nuclear matrix interactions. Nucleic Acids Research, 44, 10588-10602. https://doi.org/10. 1093/nar/gkw785

Fombonne, E. (2009). Epidemiology of pervasive developmental disorders. Pediatric Research, 65, 591-598. https://doi.org/10.1203/ PDR.0b013e31819e7203

Forum, N.Q. (2017). Surgery 2015-2017 final report

Gapp, K., Jawaid, A., Sarkies, P., Bohacek, J., Pelczar, P., Prados, J., Farinelli, L., Miska, E., \& Mansuy, I. M. (2014). Implication of sperm RNAs in transgenerational inheritance of the effects of early trauma in mice. Nature Neuroscience, 17, 667-669. https:// doi.org/10.1038/nn.3695

Gapp, K., van Steenwyk, G., Germain, P. L., Matsushima, W., Rudolph, K. L. M., Manuella, F., Roszkowski, M., Vernaz, G., Ghosh, T., Pelczar, P., Mansuy, I. M., \& Miska, E. A. (2020). Alterations in sperm long RNA contribute to the epigenetic inheritance of the effects of postnatal trauma. Molecular Psychiatry, 25, 21622174. https://doi.org/10.1038/s41380-018-0271-6

García-Rodríguez, A., Gosálvez, J., Agarwal, A., Roy, R., \& Johnston, S. (2018). DNA damage and repair in human reproductive cells.
International Journal of Molecular Sciences, 20, 31. https://doi. org/10.3390/ijms20010031

Garrido, N., Cruz, F., Egea, R. R., Simon, C., Sadler-Riggleman, I., Beck, D., Nilsson, E., Ben Maamar, M., \& Skinner, M. K. (2021). Sperm DNA methylation epimutation biomarker for paternal offspring autism susceptibility. Clinical Epigenetics, 13, 6. https://doi.org/10.1186/s13148-020-00995-2

Gazestani, V. H., Pramparo, T., Nalabolu, S., Kellman, B. P., Murray, S., Lopez, L., Pierce, K., Courchesne, E., \& Lewis, N. E. (2019). A perturbed gene network containing PI3K-AKT, RAS-ERK and WNT- $\beta$-catenin pathways in leukocytes is linked to ASD genetics and symptom severity. Nature Neuroscience, 22, 1624-1634. https://doi.org/10.1038/s41593-019-0489-x

Ge, W., Li, L., Dyce, P. W., De Felici, M., \& Shen, W. (2019). Establishment and depletion of the ovarian reserve: Physiology and impact of environmental chemicals. Cellular and Molecular Life Sciences, 76, 1729-1746. https://doi.org/10.1007/ s00018-019-03028-1

Godschalk, R. W. L., Verhofstad, N., Verheijen, M., Yauk, C., Linschooten, J. O., van Steeg, H., van Oostrom, C. T., van Benthem, J., \& van Schooten, F. J. (2015). Effects of benzo[a]pyrene on mouse germ cells: Heritable DNA mutation, testicular cell hypomethylation and their interaction with nucleotide excision repair. Toxicology Research, 4, 718-724.

Golding, J., Ellis, G., Gregory, S., Birmingham, K., Iles-Caven, Y., Rai, D., \& Pembrey, M. (2017). Grand-maternal smoking in pregnancy and grandchild's autistic traits and diagnosed autism. Science and Reports, 7, 46179. https://doi.org/10.1038/srep46179

Goldsby, J. A., Wolstenholme, J. T., \& Rissman, E. F. (2017). Multiand transgenerational consequences of bisphenol A on sexually dimorphic cell populations in mouse brain. Endocrinology, 158, 21-30. https://doi.org/10.1210/en.2016-1188

Gratten, J., Wray, N. R., Peyrot, W. J., McGrath, J. J., Visscher, P. M., \& Goddard, M. E. (2016). Risk of psychiatric illness from advanced paternal age is not predominantly from de novo mutations. Nature Genetics, 48, 718-724. https://doi.org/10.1038/ng. 3577

Grove, J., et al. (2019). Identification of common genetic risk variants for autism spectrum disorder. Nature Genetics, 51, 431-444. https://doi.org/10.1038/s41588-019-0344-8

Gupta, S., Ellis, S. E., Ashar, F. N., Moes, A., Bader, J. S., Zhan, J., West, A. B., \& Arking, D. E. (2014). Transcriptome analysis reveals dysregulation of innate immune response genes and neuronal activity-dependent genes in autism. Nature Communications, 5, 5748. https://doi.org/10.1038/ncomms6748

Haervig, K. K., Høyer, B. B., Giwercman, A., Hougaard, K. S., Ramlau-Hansen, C. H., Specht, I. O., Toft, G., Bonde, J. P., \& Søgaard Tøttenborg, S. (2020). Fetal exposure to paternal smoking and semen quality in the adult son. Andrology, 8, 1117-1125. https://doi.org/10.1111/andr.12782

Huberman Samuel, M., Meiri, G., Dinstein, I., Flusser, H., Michaelovski, A., Bashiri, A., \& Menashe, I. (2019). Exposure to general anesthesia may contribute to the association between cesarean delivery and autism spectrum disorder. Journal of Autism and Developmental Disorders, 49, 3127-3135. https:// doi.org/10.1007/s10803-019-04034-9

Ibi, D., Fujiki, Y., Koide, N., Nakasai, G., Takaba, R., \& Hiramatsu, M. (2019). Paternal valproic acid exposure in mice triggers behavioral alterations in offspring. Neurotoxicology and Teratology, 76, 106837. https://doi.org/10.1016/j.ntt.2019.106837

Ing, C., Landau, R., DeStephano, D., Miles, C. H., von Ungern-Sternberg, B. S., Li, G., \& Whitehouse, A. J. O. (2021). Prenatal exposure to general anesthesia and childhood behavioral deficit. Anesthesia and Analgesia. https://doi.org/10.1213/ane.00000 00000005389 
Janesick, A. S., \& Blumberg, B. (2016). Obesogens: an emerging threat to public health. American Journal of Obstetrics and Gynecology, 214, 559-565. https://doi.org/10.1016/j.ajog.2016.01.182

Jawaid, A., Roszkowski, M., \& Mansuy, I. M. (2018). Transgenerational epigenetics of traumatic stress. Progress in Molecular Biology and Translational Science, 158, 273-298. https://doi. org/10.1016/bs.pmbts.2018.03.003

Ju, L. S., Yang, J. J., Morey, T. E., Gravenstein, N., Seubert, C. N., Resnick, J. L., Zhang, J. Q., \& Martynyuk, A. E. (2018). Role of epigenetic mechanisms in transmitting the effects of neonatal sevoflurane exposure to the next generation of male, but not female, rats. British Journal of Anaesthesia, 121, 406-416. https://doi.org/10.1016/j.bja.2018.04.034

Ju, L. S., Yang, J. J., Xu, N., Li, J., Morey, T. E., Gravenstein, N., Seubert, C. N., Setlow, B., \& Martynyuk, A. E. (2019). Intergenerational effects of sevoflurane in young adult rats. Anesthesiology, 131, 1092-1109. https://doi.org/10.1097/aln.0000000000002920

Jung, Y. H., Bixler, B. J., Ruiz, D., Wang, H. L., Lisenbaum, H., Xiang, J.-F., Shafik, A. M., Jin, P., \& Corces, V. G. (2020). Transgenerational inheritance of BPA-induced obesity correlates with transmission of new CTCF sites in the Fto gene. bioRxiv. https://doi. org/10.1101/20201120391672

Jung, Y. H., Kremsky, I., Gold, H. B., Rowley, M. J., Punyawai, K., Buonanotte, A., Lyu, X., Bixler, B. J., Chan, A. W. S., \& Corces, V. G. (2019). Maintenance of CTCF- and transcription factormediated interactions from the gametes to the early mouse embryo. Molecular Cell, 75, 154-171.e5. https://doi.org/10. 1016/j.molcel.2019.04.014

Kaplanis, J., Ide, B., Sanghvi, R., Neville, M., Danecek, P., Prigmore, E., Short, P., Gallone, G., McRae, J., Odhams, C., Moutsianas, L., Consortium, G. E. R., Carmichael, J., Barnicoat, A., Firth, H., O'Brien, P., Rahbari, R., \& Hurles, M. (2021). Genetic and pharmacological causes of germline hypermutation. bioRxiv. https://doi.org/10.1101/2021.06.01.446180

Kaya, Z., Sogut, E., Cayli, S., Suren, M., Arici, S., Karaman, S., \& Erdemir, F. (2013). Evaluation of effects of repeated sevoflurane exposure on rat testicular tissue and reproductive hormones. Inhalation Toxicology, 25, 192-198. https://doi.org/10.3109/ 08958378.2013.773109

Kaymak, C., Kadioglu, E., Coskun, E., Basar, H., \& Basar, M. (2012). Determination of DNA damage after exposure to inhalation anesthetics in human peripheral lymphocytes and sperm cells in vitro by comet assay. Human and Experimental Toxicology, 31, 1207-1213. https://doi.org/10.1177/0960327112446818

Kim, B., Ha, M., Kim, Y. S., Koh, Y. J., Dong, S., Kwon, H. J., Kim, Y. S., Lim, M. H., Paik, K. C., Yoo, S. J., Kim, H., Hong, P. S., Sanders, S. J., \& Leventhal, B. L. (2021). Prenatal exposure to paternal smoking and likelihood for autism spectrum disorder. Autism. https://doi.org/10.1177/13623613211007319

Kioumourtzoglou, M. A., Coull, B. A., O’Reilly, É. J., Ascherio, A., \& Weisskopf, M. G. (2018). Association of exposure to diethylstilbestrol during pregnancy with multigenerational neurodevelopmental deficits. JAMA Pediatrics, 172, 670-677. https://doi. org/10.1001/jamapediatrics.2018.0727

Kremsky, I., \& Corces, V. G. (2020). Protection from DNA re-methylation by transcription factors in primordial germ cells and preimplantation embryos can explain trans-generational epigenetic inheritance. Genome Biology, 21, 118. https://doi.org/10.1186/ s13059-020-02036-w

Krishnan, K., Hasbum, A., Morales, D., Thompson, L. M., Crews, D., \& Gore, A. C. (2019). Endocrine-disrupting chemicals alter the neuromolecular phenotype in F2 generation adult male rats. Physiology \& Behavior, 211, 112674. https://doi.org/10.1016/j. physbeh.2019.112674

Krishnan, K., Mittal, N., Thompson, L. M., Rodriguez-Santiago, M., Duvauchelle, C. L., Crews, D., \& Gore, A. C. (2018). Effects of the endocrine-disrupting chemicals, vinclozolin and polychlorinated biphenyls, on physiological and sociosexual phenotypes in F2 generation Sprague-Dawley rats. Environmental Health Perspectives, 126, 97005. https://doi.org/10.1289/ehp3550

Kurimoto, K., \& Saitou, M. (2019a). Germ cell reprogramming. Current Topics in Developmental Biology, 135, 91-125. https://doi. org/10.1016/bs.ctdb.2019.04.005

Lakshmanan, M. D., \& Shaheer, K. (2020). Endocrine disrupting chemicals may deregulate DNA repair through estrogen receptor mediated seizing of $\mathrm{CBP} / \mathrm{p} 300$ acetylase. Journal of Endocrinological Investigation, 43, 1189-1196. https://doi.org/10.1007/ s40618-020-01241-5

Land, P. C., Owen, E. L., \& Linde, H. W. (1981). Morphologic changes in mouse spermatozoa after exposure to inhalational anesthetics during early spermatogenesis. Anesthesiology, 54, 53-56. https:// doi.org/10.1097/00000542-198101000-00010

Larose, H., Shami, A. N., Abbott, H., Manske, G., Lei, L., \& Hammoud, S. S. (2019). Gametogenesis: A journey from inception to conception. Current Topics in Developmental Biology, 132, 257-310. https://doi.org/10.1016/bs.ctdb.2018.12.006

Laubenthal, J., Zlobinskaya, O., Poterlowicz, K., Baumgartner, A., Gdula, M. R., Fthenou, E., Keramarou, M., Hepworth, S. J., Kleinjans, J. C., van Schooten, F. J., Brunborg, G., Godschalk, R. W., Schmid, T. E., \& Anderson, D. (2012). Cigarette smokeinduced transgenerational alterations in genome stability in cord blood of human F1 offspring. The FASEB Journal, 26, 39463956. https://doi.org/10.1096/fj.11-201194

Lee, B. K., Gardner, R. M., Dal, H., Svensson, A., Galanti, M. R., Rai, D., Dalman, C., \& Magnusson, C. (2012). Brief report: Maternal smoking during pregnancy and autism spectrum disorders. Journal of Autism and Developmental Disorders, 42, 2000-2005. https://doi.org/10.1007/s10803-011-1425-4

Lempradl, A. (2020). Germ cell-mediated mechanisms of epigenetic inheritance. Seminars in Cell \& Developmental Biology, 97, 116-122. https://doi.org/10.1016/j.semcdb.2019.07.012

Li, T., Huang, Z., Wang, X., Zou, J., \& Tan, S. (2019). Role of the GABAA receptors in the long-term cognitive impairments caused by neonatal sevoflurane exposure. Reviews in the Neurosciences, 30, 869-879. https://doi.org/10.1515/revne uro-2019-0003

Linschooten, J. O., Verhofstad, N., Gutzkow, K., Olsen, A. K., Yauk, C., Oligschläger, Y., Brunborg, G., van Schooten, F. J., \& Godschalk, R. W. (2013). Paternal lifestyle as a potential source of germline mutations transmitted to offspring. The FASEB Journal, 27, 2873-2879. https://doi.org/10.1096/fj.13-227694

Lord, C., Brugha, T. S., Charman, T., Cusack, J., Dumas, G., Frazier, T., Jones, E. J. H., Jones, R. M., Pickles, A., State, M. W., Taylor, J. L., \& Veenstra-VanderWeele, J. (2020). Autism spectrum disorder. Nature Reviews. Disease Primers, 6, 5. https://doi.org/ 10.1038/s41572-019-0138-4

Maenner, M. J., et al. (2020). Prevalence of autism spectrum disorder among children aged 8 years-autism and developmental disabilities monitoring network, 11 sites, United States, 2016. MMWR Surveillance Summaries, 69, 1-12. https://doi.org/10. 15585/mmwr.ss6904a1

Manners, M. T., Yohn, N. L., Lahens, N. F., Grant, G. R., Bartolomei, M. S., \& Blendy, J. A. (2019). Transgenerational inheritance of chronic adolescent stress: Effects of stress response and the amygdala transcriptome. Genes, Brain, and Behavior, 18, e12493. https://doi.org/10.1111/gbb.12493

Marchetti, F., \& Wyrobek, A. J. (2005). Mechanisms and consequences of paternally-transmitted chromosomal abnormalities. Birth Defects Research. Part C, Embryo Today, 75, 112-129. https:// doi.org/10.1002/bdrc.20040

Martinez, M. E., Duarte, C. W., Stohn, J. P., Karaczyn, A., Wu, Z., DeMambro, V. E., \& Hernandez, A. (2020). Thyroid hormone 
influences brain gene expression programs and behaviors in later generations by altering germ line epigenetic information. Molecular Psychiatry, 25, 939-950. https://doi.org/10.1038/ s41380-018-0281-4

Martini, M., Corces, V. G., \& Rissman, E. F. (2020). Mini-review: Epigenetic mechanisms that promote transgenerational actions of endocrine disrupting chemicals: Applications to behavioral neuroendocrinology. Hormones and Behavior, 119, 104677. https:// doi.org/10.1016/j.yhbeh.2020.104677

Martynyuk, A. E., Ju, L. S., Morey, T. E., \& Zhang, J. Q. (2020). Neuroendocrine, epigenetic, and intergenerational effects of general anesthetics. World J Psychiatry, 10, 81-94. https://doi.org/10. 5498/wjp.v10.i5.81

McCanlies, E. C., Ma, C. C., Gu, J. K., Fekedulegn, D., Sanderson, W. T., Ludeña-Rodriguez, Y. J., \& Hertz-Picciotto, I. (2019). The CHARGE study: An assessment of parental occupational exposures and autism spectrum disorder. Occupational and Environmental Medicine, 76, 644-651. https://doi.org/10.1136/ oemed-2018-105395

McCarthy, D. M., Lowe, S. E., Morgan, T. J., Cannon, E. N., Biederman, J., Spencer, T. J., \& Bhide, P. G. (2020). Transgenerational transmission of behavioral phenotypes produced by exposure of male mice to saccharin and nicotine. Science and Reports, 10, 11974. https://doi.org/10.1038/s41598-020-68883-6

McGee, G., Perkins, N. J., Mumford, S. L., Kioumourtzoglou, M. A., Weisskopf, M. G., Schildcrout, J. S., Coull, B. A., Schisterman, E. F., \& Haneuse, S. (2020). Methodological issues in population-based studies of multigenerational associations. American Journal of Epidemiology, 189, 1600-1609. https://doi.org/10. 1093/aje/kwaa125

Moisiadis, V. G., Constantinof, A., Kostaki, A., Szyf, M., \& Matthews, S. G. (2017). Prenatal glucocorticoid exposure modifies endocrine function and behaviour for 3 generations following maternal and paternal transmission. Science and Reports, 7, 11814. https://doi.org/10.1038/s41598-017-11635-w

Morgan, C. P., \& Bale, T. L. (2011). Early prenatal stress epigenetically programs dysmasculinization in second-generation offspring via the paternal lineage. Journal of Neuroscience, 31, 11748-11755. https://doi.org/10.1523/jneurosci.1887-11.2011

Mruk, D. D., \& Cheng, C. Y. (2015). The mammalian blood-testis barrier: Its biology and regulation. Endocrine Reviews, 36, 564-591. https://doi.org/10.1210/er.2014-1101

Murphy, S. K., Itchon-Ramos, N., Visco, Z., Huang, Z., Grenier, C., Schrott, R., Acharya, K., Boudreau, M. H., Price, T. M., Raburn, D. J., Corcoran, D. L., Lucas, J. E., Mitchell, J. T., McClernon, F. J., Cauley, M., Hall, B. J., Levin, E. D., \& Kollins, S. H. (2018). Cannabinoid exposure and altered DNA methylation in rat and human sperm. Epigenetics, 13, 1208-1221. https://doi.org/10. 1080/15592294.2018.1554521

Myers, M., \& Hutt, K. J. (2013). Damage control in the female germline: Protecting primordial follicles. In G. Coticchio, D. Albertini, \& L. De Santis (Eds.), Oogenesis London. Springer.

Myers, S. M., Challman, T. D., Bernier, R., Bourgeron, T., Chung, W. K., Constantino, J. N., Eichler, E. E., Jacquemont, S., Miller, D. T., Mitchell, K. J., Zoghbi, H. Y., Martin, C. L., \& Ledbetter, D. H. (2020). Insufficient evidence for "autism-specific" genes. American Journal of Human Genetics, 106, 587-595. https://doi. org/10.1016/j.ajhg.2020.04.004

Neto, F. T., Bach, P. V., Najari, B. B., Li, P. S., \& Goldstein, M. (2016). Spermatogenesis in humans and its affecting factors. Seminars in Cell \& Developmental Biology, 59, 10-26. https://doi.org/10. 1016/j.semcdb.2016.04.009

Nevison, C. D. (2014). A comparison of temporal trends in United States autism prevalence to trends in suspected environmental factors. Environmental Health, 13, 73. https://doi.org/10.1186/ 1476-069X-13-73
Orsi, N. M., Baskind, N. E., \& Cummings, M. (2014). Anatomy, development, histology, and normal function of the ovary. In N. Wilkinson (Ed.), Pathology of the ovary. Fallopian Tube and Peritoneum Essentials of Diagnostic Gynecological Pathology London.

Ozgyin, L., Erdos, E., Bojcsuk, D., \& Balint, B. L. (2015). Nuclear receptors in transgenerational epigenetic inheritance. Progress in Biophysics and Molecular Biology, 118, 34-43. https://doi. org/10.1016/j.pbiomolbio.2015.02.012

Palmer, N., Beam, A., Agniel, D., Eran, A., Manrai, A., Spettell, C., Steinberg, G., Mandl, K., Fox, K., Nelson, S. F., \& Kohane, I. (2017). Association of sex with recurrence of autism spectrum disorder among siblings. JAMA Pediatrics, 171, 1107-1112. https://doi.org/10.1001/jamapediatrics.2017.2832

Patron, J., Serra-Cayuela, A., Han, B., Li, C., \& Wishart, D. S. (2019). Assessing the performance of genome-wide association studies for predicting disease risk. PLoS ONE, 14, e0220215. https://doi. org/10.1371/journal.pone.0220215

Pereanu, W., Larsen, E. C., Das, I., Estevez, M. A., Sarkar, A. A., Spring-Pearson, S., Kollu, R., Basu, S. N., \& Banerjee-Basu, S. (2018). AutDB: A platform to decode the genetic architecture of autism. Nucleic Acids Research, 46, D1049-D1054. https://doi. org/10.1093/nar/gkx1093

Perera, B. P. U., Faulk, C., Svoboda, L. K., Goodrich, J. M., \& Dolinoy, D. C. (2020). The role of environmental exposures and the epigenome in health and disease. Environmental and Molecular Mutagenesis, 61, 176-192. https://doi.org/10.1002/em.22311

Phillips, B. T., Gassei, K., \& Orwig, K. E. (2010). Spermatogonial stem cell regulation and spermatogenesis. Philosophical Transactions of the Royal Society of London. Series B, Biological Sciences, 365, 1663-1678. https://doi.org/10.1098/rstb.2010.0026

Power, R. A., Kyaga, S., Uher, R., MacCabe, J. H., Långström, N., Landen, M., McGuffin, P., Lewis, C. M., Lichtenstein, P., \& Svensson, A. C. (2013). Fecundity of patients with schizophrenia, autism, bipolar disorder, depression, anorexia nervosa, or substance abuse vs their unaffected siblings. JAMA Psychiatry, 70, 22-30. https://doi.org/10.1001/jamapsychiatry.2013.268

Pugsley, K., Scherer, S. W., Bellgrove, M. A., \& Hawi, Z. (2021). Environmental exposures associated with elevated risk for autism spectrum disorder may augment the burden of deleterious de novo mutations among probands. Molecular Psychiatry. https://doi.org/10.1038/s41380-021-01142-w

Quesnel-Vallières, M., Weatheritt, R. J., Cordes, S. P., \& Blencowe, B. J. (2019). Autism spectrum disorder: Insights into convergent mechanisms from transcriptomics. Nature Reviews Genetics, 20, 51-63. https://doi.org/10.1038/s41576-018-0066-2

Reinisch, J. M., \& Karow, W. G. (1977). Prenatal exposure to synthetic progestins and estrogens: Effects on human development. Archives of Sexual Behavior, 6, 257-288. https://doi.org/10. 1007/bf01541201

Rodgers, A. B., Morgan, C. P., Bronson, S. L., Revello, S., \& Bale, T. L. (2013). Paternal stress exposure alters sperm microRNA content and reprograms offspring HPA stress axis regulation. Journal of Neuroscience, 33, 9003-9012. https://doi.org/10. 1523/jneurosci.0914-13.2013

Rodgers, A. B., Morgan, C. P., Leu, N. A., \& Bale, T. L. (2015). Transgenerational epigenetic programming via sperm microRNA recapitulates effects of paternal stress. Proceedings of the National Academy of Sciences USA, 112, 13699-13704. https://doi.org/10.1073/pnas.1508347112

Rosen, B. N., Lee, B. K., Lee, N. L., Yang, Y., \& Burstyn, I. (2015). Maternal smoking and autism spectrum disorder: A metaanalysis. Journal of Autism and Developmental Disorders, 45, 1689-1698. https://doi.org/10.1007/s10803-014-2327-z

Roullet, F. I., Lai, J. K., \& Foster, J. A. (2013). In utero exposure to valproic acid and autism-a current review of clinical and 
animal studies. Neurotoxicology and Teratology, 36, 47-56. https://doi.org/10.1016/j.ntt.2013.01.004

Rubenstein, E., \& Chawla, D. (2018). Broader autism phenotype in parents of children with autism: A systematic review of percentage estimates. Journal of Child and Family Studies, 27, 1705-1720. https://doi.org/10.1007/s10826-018-1026-3

Saavedra-Rodríguez, L., \& Feig, L. A. (2013). Chronic social instability induces anxiety and defective social interactions across generations. Biological Psychiatry, 73, 44-53. https://doi.org/ 10.1016/j.biopsych.2012.06.035

Sales, V. M., Ferguson-Smith, A. C., \& Patti, M. E. (2017). Epigenetic mechanisms of transmission of metabolic disease across generations. Cell Metabolism, 25, 559-571. https://doi.org/10. 1016/j.cmet.2017.02.016

Samaco, R. C., Hogart, A., \& LaSalle, J. M. (2005). Epigenetic overlap in autism-spectrum neurodevelopmental disorders: MECP2 deficiency causes reduced expression of UBE3A and GABRB3. Human Molecular Genetics, 14, 483-492.

Sanchez, F., \& Smitz, J. (2012). Molecular control of oogenesis. Biochimica Et Biophysica Acta, 1822, 1896-1912. https://doi. org/10.1016/j.bbadis.2012.05.013

Sandin, S., Lichtenstein, P., Kuja-Halkola, R., Hultman, C., Larsson, H., \& Reichenberg, A. (2017). The heritability of autism spectrum disorder. JAMA, 318, 1182-1184. https://doi.org/10. 1001/jama.2017.12141

Sandin, S., Lichtenstein, P., Kuja-Halkola, R., Larsson, H., Hultman, C. M., \& Reichenberg, A. (2014). The familial risk of autism. JAMA, 311, 1770-1777. https://doi.org/10.1001/jama. 2014.4144

SanMiguel, J. M., \& Bartolomei, M. S. (2018). DNA methylation dynamics of genomic imprinting in mouse development. Biology of Reproduction, 99, 252-262. https://doi.org/10.1093/biolre/ ioy036

Schendel, D. E., \& Thorsteinsson, E. (2018). Cumulative incidence of autism into adulthood for birth cohorts in Denmark, 1980-2012. JAMA, 320, 1811-1813. https://doi.org/10.1001/jama.2018. 11328

Schifilliti, D., Mondello, S., D’Arrigo, M. G., Chillè, G., \& Fodale, V. (2011). Genotoxic effects of anesthetic agents: An update. Expert Opinion on Drug Safety, 10, 891-899. https://doi.org/ $10.1517 / 14740338.2011 .586627$

Schrott, R., \& Murphy, S. K. (2020). Cannabis use and the sperm epigenome: A budding concern? Environmental Epigenetics, 6, dvaa002. https://doi.org/10.1093/eep/dvaa002

Schrott, R., Rajavel, M., Acharya, K., Huang, Z., Acharya, C., Hawkey, A., Pippen, E., Lyerly, H. K., Levin, E. D., \& Murphy, S. K. (2020). Sperm DNA methylation altered by THC and nicotine: Vulnerability of neurodevelopmental genes with bivalent chromatin. Science and Reports, 10, 16022. https:// doi.org/10.1038/s41598-020-72783-0

Scordalakes, E. M., \& Rissman, E. F. (2004). Aggression and arginine vasopressin immunoreactivity regulation by androgen receptor and estrogen receptor alpha. Genes, Brain, and Behavior, 3, 20-26. https://doi.org/10.1111/j.1601-183x.2004. 00036.x

Seisenberger, S., Peat, J. R., Hore, T. A., Santos, F., Dean, W., \& Reik, W. (2013). Reprogramming DNA methylation in the mammalian life cycle: Building and breaking epigenetic barriers. Philosophical Transactions of the Royal Society B: Biological Sciences, 368, 20110330. https://doi.org/10.1098/rstb.2011.0330

Short, A. K., Fennell, K. A., Perreau, V. M., Fox, A., O'Bryan, M. K., Kim, J. H., Bredy, T. W., Pang, T. Y., \& Hannan, A. J. (2016). Elevated paternal glucocorticoid exposure alters the small noncoding RNA profile in sperm and modifies anxiety and depressive phenotypes in the offspring. Translational Psychiatry, 6, e837. https://doi.org/10.1038/tp.2016.109
Smrcek, J. M., Schwartau, N., Kohl, M., Berg, C., Geipel, A., Krapp, M., Diedrich, K., \& Ludwig, M. (2005). Antenatal corticosteroid therapy in premature infants. Archives of Gynecology and Obstetrics, 271, 26-32. https://doi.org/10.1007/s00404-004-0664-4

Tang, C. K., Chalon, J., Markham, J. P., Ramanathan, S., \& Turndorf, H. (1984). Exposure of sires to enflurane affects learning function of murine progeny. Anesthesia and Analgesia, 63, 729-730.

Tang, W. W., Dietmann, S., Irie, N., Leitch, H. G., Floros, V. I., Bradshaw, C. R., Hackett, J. A., Chinnery, P. F., \& Surani, M. A. (2015a). A unique gene regulatory network resets the human germline epigenome for development. Cell, 161, 1453-1467. https://doi.org/10.1016/j.cell.2015.04.053

Tang, X. N., Yao, W., Yao, H. X., Zhang, Y., \& Yue, J. (2020). Influence of isoflurane exposure for 15 consecutive days on ovarian function in adult female mice. Current Medical Science, 40, 1177-1181. https://doi.org/10.1007/s11596-020-2300-3

Tartaglione, A. M., Cipriani, C., Chiarotti, F., Perrone, B., Balestrieri, E., Matteucci, C., Sinibaldi-Vallebona, P., Calamandrei, G., \& Ricceri, L. (2019). Early behavioral alterations and increased expression of endogenous retroviruses are inherited across generations in mice prenatally exposed to valproic acid. Molecular Neurobiology, 56, 3736-3750. https://doi.org/10.1007/ s12035-018-1328-x

The Simons Vip Consortium. (2012). Simons variation in individuals project (Simons VIP): A genetics-first approach to studying autism spectrum and related neurodevelopmental disorders. Neuron, 73, 1063-1067. https://doi.org/10.1016/j.neuron.2012. 02.014

Tick, B., Bolton, P., Happe, F., Rutter, M., \& Rijsdijk, F. (2016). Heritability of autism spectrum disorders: A meta-analysis of twin studies. Journal of Child Psychology and Psychiatry, 57, 585595. https://doi.org/10.1111/jcpp.12499

Tomson, T., Muraca, G., \& Razaz, N. (2020). Paternal exposure to antiepileptic drugs and offspring outcomes: A nationwide population-based cohort study in Sweden. Journal of Neurology, Neurosurgery and Psychiatry, 91, 907-913. https://doi.org/10. 1136/jnnp-2020-323028

Voineagu, I., Wang, X., Johnston, P., Lowe, J. K., Tian, Y., Horvath, S., Mill, J., Cantor, R. M., Blencowe, B. J., \& Geschwind, D. H. (2011). Transcriptomic analysis of autistic brain reveals convergent molecular pathology. Nature, 474, 380-384. https://doi.org/ 10.1038 /nature 10110

von Ehrenstein, O. S., Cui, X., Yan, Q., Aralis, H., \& Ritz, B. (2020). Maternal prenatal smoking and autism spectrum disorder in offspring: A California Statewide Cohort and Sibling Study. American Journal of Epidemiology, 190, 728-737. https://doi.org/10. 1093/aje/kwaa182

Vutskits, L., Sall, J. W., \& Jevtovic-Todorovic, V. (2018). A poisoned chalice: The heritage of parental anaesthesia exposure. British Journal of Anaesthesia, 121, 337-339. https://doi.org/10.1016/j. bja.2018.05.013

Wang, H. V., Forestier, S., \& Corces, V. G. (2021). Exposure to sevoflurane results in changes of transcription factor occupancy in sperm and inheritance of autism. Biology of Reproduction, 105, 705-719. https://doi.org/10.1093/biolre/ioab097

Wang, H. W., Zhao, W. P., Liu, J., Tan, P. P., Zhang, C., \& Zhou, B. H. (2017). Fluoride-induced oxidative stress and apoptosis are involved in the reducing of oocytes development potential in mice. Chemosphere, 186, 911-918. https://doi.org/10.1016/j. chemosphere.2017.08.068

Wang, L. J., Wang, X. H., Sun, H. J., \& Xu, B. (2008). Effects of inhalation anaesthetics on human sperm motility and vitality in vitro. British Journal of Anaesthesia, 101, 883-884. https://doi.org/10. 1093/bja/aen307

Warner, D. O., Zaccariello, M. J., Katusic, S. K., Schroeder, D. R., Hanson, A. C., Schulte, P. J., Buenvenida, S. L., Gleich, S. J., 
Wilder, R. T., Sprung, J., Hu, D., Voigt, R. G., Paule, M. G., Chelonis, J. J., \& Flick, R. P. (2018). Neuropsychological and behavioral outcomes after exposure of young children to procedures requiring general anesthesia: The Mayo Anesthesia Safety in Kids (MASK) Study. Anesthesiology, 129, 89-105. https://doi. org/10.1097/aln.0000000000002232

Weiser, T. G., Haynes, A. B., Molina, G., Lipsitz, S. R., Esquivel, M. M., Uribe-Leitz, T., Fu, R., Azad, T., Chao, T. E., Berry, W. R., \& Gawande, A. A. (2016). Size and distribution of the global volume of surgery in 2012. Bulletin of the World Health Organization, 94, 201-209F. https://doi.org/10.2471/BLT.15.159293

Wen, L., \& Tang, F. (2019). Human germline cell development: From the perspective of single-cell sequencing. Molecular Cell, 76, 320-328. https://doi.org/10.1016/j.molcel.2019.08.025

Whalen, F. X., Bacon, D. R., \& Smith, H. M. (2005). Inhaled anesthetics: An historical overview. Best Practice \& Research Clinical Anaesthesiology, 19, 323-330. https://doi.org/10.1016/j.bpa. 2005.02.001

Wolstenholme, J. T., Drobná, Z., Henriksen, A. D., Goldsby, J. A., Stevenson, R., Irvin, J. W., Flaws, J. A., \& Rissman, E. F. (2019). Transgenerational bisphenol A causes deficits in social recognition and alters postsynaptic density genes in mice. Endocrinology, 160, 1854-1867. https://doi.org/10.1210/en.2019-00196

Wolstenholme, J. T., Edwards, M., Shetty, S. R., Gatewood, J. D., Taylor, J. A., Rissman, E. F., \& Connelly, J. J. (2012). Gestational exposure to bisphenol a produces transgenerational changes in behaviors and gene expression. Endocrinology, 153, 3828-3838. https://doi.org/10.1210/en.2012-1195

Wouters-Tyrou, D., Martinage, A., Chevaillier, P., \& Sautière, P. (1998). Nuclear basic proteins in spermiogenesis. Biochimie, 80, 117-128. https://doi.org/10.1016/s0300-9084(98)80018-7

Xiao, J., Gao, Y., Yu, Y., Toft, G., Zhang, Y., Luo, J., Xia, Y., Chawarska, K., Olsen, J., Li, J., \& Liew, Z. (2021). Associations of parental birth characteristics with autism spectrum disorder (ASD) risk in their offspring: A population-based multigenerational cohort study in Denmark. International Journal of Epidemiology, 50, 485-495. https://doi.org/10.1093/ije/dyaa246

Xu, N., Lei, L., Lin, Y., Ju, L. S., Morey, T. E., Gravenstein, N., Yang, J., \& Martynyuk, A. E. (2020). A methyltransferase inhibitor (decitabine) alleviates intergenerational effects of paternal neonatal exposure to anesthesia with sevoflurane. Anesthesia and Analgesia, 131, 1291-1299. https://doi.org/10.1213/ane.00000 00000005097
Xu, X. L., Pan, C., Hu, J. X., Liu, X. T., Li, Y. F., Wang, H., Chen, Y. B., Dong, H. Y., Dai, T. J., \& Xu, L. C. (2012). Effects of isoflurane inhalation on the male reproductive system in rats. Environmental Toxicology and Pharmacology, 34, 688-693. https:// doi.org/10.1016/j.etap.2012.09.020

Yang, Y., Lin, J., Lu, X., Xun, G., Wu, R., Li, Y., Ou, J., Shen, Y., Xia, K., \& Zhao, J. (2021). Anesthesia, sex and miscarriage history may influence the association between cesarean delivery and autism spectrum disorder. BMC Pediatrics, 21, 62. https://doi. org/10.1186/s12887-021-02518-1

Yeshurun, S., \& Hannan, A. J. (2019). Transgenerational epigenetic influences of paternal environmental exposures on brain function and predisposition to psychiatric disorders. Molecular Psychiatry, 24, 536-548. https://doi.org/10.1038/s41380-018-0039-z

Young, L. J., Wang, Z., Donaldson, R., \& Rissman, E. F. (1998). Estrogen receptor $\alpha$ is essential for induction of oxytocin receptor by estrogen. NeuroReport, 9, 933-936.

Yu, B., Dong, X., Gravina, S., Kartal, O., Schimmel, T., Cohen, J., Tortoriello, D., Zody, R., Hawkins, R. D., \& Vijg, J. (2017). Genome-wide, single-cell DNA methylomics reveals increased non-CpG methylation during human oocyte maturation. Stem Cell Reports, 9, 397-407. https://doi.org/10.1016/j.stemcr.2017. 05.026

Yuen, R. K., et al. (2015). Whole-genome sequencing of quartet families with autism spectrum disorder. Nature Medicine, 21, 185191. https://doi.org/10.1038/nm.3792

Zafeiriou, D. I., Ververi, A., Dafoulis, V., Kalyva, E., \& Vargiami, E. (2013). Autism spectrum disorders: The quest for genetic syndromes. American Journal of Medical Genetics Part B: Neuropsychiatric Genetics, 162B, 327-366. https://doi.org/10.1002/ ajmg.b.32152

Zhu, J., Lee, K. P., Spencer, T. J., Biederman, J., \& Bhide, P. G. (2014). Transgenerational transmission of hyperactivity in a mouse model of ADHD. Journal of Neuroscience, 34, 2768-2773. https://doi.org/10.1523/jneurosci.4402-13.2014

Publisher's Note Springer Nature remains neutral with regard to jurisdictional claims in published maps and institutional affiliations. 